\title{
Improved Cardiac Outcomes by Early Treatment with Angiotensin-Converting Enzyme Inhibitors in Becker Muscular Dystrophy
}

Caroline Stalens ${ }^{\mathrm{a}, \mathrm{b}}$, Leslie Mottéc ${ }^{\mathrm{c}}$, Anthony Béhin ${ }^{\mathrm{d}}$, Rabah Ben Yaou ${ }^{\mathrm{d}}$, France Leturcq ${ }^{\mathrm{e}}$, Guillaume Bassez $^{\mathrm{d}}$, Pascal Laforêt ${ }^{\mathrm{f}}$, Bertrand Fontaine ${ }^{\mathrm{d}}$, Stéphane Ederhy ${ }^{\mathrm{g}}$, Marion Masingue ${ }^{\mathrm{d}}$, Malika Saadi $^{c}$, Sarah Leonard Louis ${ }^{d}$, Nawal Berber ${ }^{d}$, Tanya Stojkovic ${ }^{d}$, Denis Duboc ${ }^{\mathrm{c}, \mathrm{h}}$ and Karim Wahbi ${ }^{\mathrm{c}, \mathrm{h}, \mathrm{i}, *}$

${ }^{a}$ Medical Affairs Department, AFM-Téléthon, Evry, France

${ }^{\mathrm{b}}$ INSERM Unit 970, Paris Cardiovascular Research Centre (PARCC), Paris, France

${ }^{\mathrm{c}}$ AP-HP, Cochin Hospital, Cardiology Department, Paris, France

${ }^{\mathrm{d}}$ AP-HP, Pitié-Salpêtrière Hospital, Reference Center for Muscle Diseases Paris-Est, Myology Institute, Paris, France

e AP-HP, Cochin Hospital, Department of Genetics and Molecular Biology, Paris, France

${ }^{\mathrm{f}}$ Neurology Department, CHU Paris IdF Ouest-Hôpital Raymond Poincaré, Garches, France

$\mathrm{g}_{\text {AP-HP, Saint Antoine Hospital, Cardiology Department, Paris, France }}$

${ }^{\mathrm{h}}$ Université Paris Descartes-Sorbonne Paris Cité, Paris, France

${ }^{\mathrm{i}}$ Inserm, UMRS, Paris, France

Pre-press 29 March 2021

\begin{abstract}
.
Background: The latest practice guidelines from the American College of Cardiology/American Heart Association recommend the prescription of an ACE-i for patients presenting with non-ischemic cardiomyopathy when left ventricular ejection fraction (LVEF) falls below $40 \%$.

Objective: To determine if the initiation of treatment with an angiotensin-converting enzyme inhibitor (ACE-i) earlier than recommended by practice guidelines issued by professional societies improves the long-term cardiac outcomes of patients presenting with Becker muscular dystrophy (MD) cardiomyopathy.

Methods: From a multicenter registry of Becker MD, we selected retrospectively patients presenting between January 1990 and April 2019 with a LVEF $\geq 40$ and $\leq 49 \%$. We used a propensity score analysis to compare the risk of a) hospitalization for management of heart failure (HF), and b) a decrease in LVEF to $<35 \%$ in patients who received an ACE-i when LVEF fell below $40 \%$ (conventional treatment), versus below $50 \%$ (early treatment).

Results: From the 183 patients entered in our registry, we identified 85 whose LVEF was between 40 and $49 \%, 51$ of whom received early and 34 received conventional ACE-i treatment. Among patients with early versus conventional treatments, 2 (3.9\%) versus $4(11.8 \%)$ were hospitalized for management of HF [hazard ratio (HR) 0.151 ; $95 \%$ confidence interval (CI) 0.028 to $0.822 ; p=0.029$ ], and $9(17.6 \%$ ) versus 10 (29.4\%) had a decrease in LVEF below 35\% (HR 0.290; $95 \%$ CI 0.121 to $0.694 ; p=0.005)$.
\end{abstract}

\footnotetext{
*Correspondence to: Karim Wahbi, MD, PhD., Cardiology Department, Cochin Hospital, 27 rue du Faubourg Saint Jacques,
}

75679 PARIS Cedex 14, France. Tel.: +3315841 16 53; Fax: +33 158411605 ; E-mail: karim.wahbi@aphp.fr. 
Conclusions: The long-term cardiac outcome of patients presenting with Becker MD was significantly better when treatment with ACE-i was introduced after a decrease in LVEF below 50\%, instead of below $40 \%$ as recommended in the current practice guidelines issued by professional societies.

Keywords: Becker muscular dystrophy, non-ischemic cardiomyopathy, inherited myopathy, angiotensin-converting enzyme inhibitor, heart failure

\section{ABBREVIATIONS}

ACE-i angiotensin-converting enzyme inhibitors

aSMD absolute standardized mean difference

CI confidence interval

EF ejection fraction

HF heart failure

IPTW inverse probability of treatment weighting

LV left ventricular

MD muscular dystrophy

\section{INTRODUCTION}

Dystrophinopathies are X-linked inherited disorders caused by mutations in the $D M D$ gene, associated with altered expression of dystrophin in skeletal and cardiac muscles and progressive muscle wasting and weakness. Out-of-frame $D M D$ mutations generally result in an absence of dystrophin expression and with loss of ambulation in early teens known as Duchenne muscular dystrophy (MD), while in-frame mutations are associated with residual dystrophin expression and milder muscle involvement known as Becker MD [1-5].

The prevalence of dilated cardiomyopathy in patients presenting with dystrophinopathies reaches 75\% in Duchenne MD and is between 17 and $74 \%$ in Becker MD [2,6]. The prevention of endstage heart failure (HF), one of the most common causes of death in these patients, is central in their management [2, 4, 7-9]. In children presenting with Duchenne MD and a preserved left ventricular (LV) systolic function, treatment with an angiotensin-converting enzyme inhibitor (ACE-i) introduced by the age of 10 years prevents the development of dilated cardiomyopathy and improves the vital prognosis [10-17]. These therapeutic benefits have not been verified in patients suffering from Becker MD, who are treated with an ACE-i when the LV ejection fraction (EF) falls either below $40 \%$, based on the recommendations of the American College of Cardiology/American Heart Association professional societies to prevent the development of HF in non-ischemic cardiomyopathy
[18] or below 50\%, with the assumption of obtaining a beneficial effect similar to that observed in Duchenne MD.

The objective of this study was to determine which of these two strategies is most successful in improving the cardiac prognosis of patients presenting with Becker MD.

\section{METHODS}

\section{The Becker Heart Registry}

The Becker Heart Registry was designed and organized by the cardiology department of Cochin hospital and the neurology units of the Myology Institute of Pitié-Salpêtrière and Garches hospitals, and registered with ClinicalTrials.gov (Identifier: NCT02020954). We retrospectively included in this Registry patients 1) $\geq 18$ years of age, 2) with pathogenic variants in the $D M D$ gene without loss of ambulation before the age of 13 years, corresponding to a Duchenne MD phenotype, and 3) referred to our units between January 1990 and April 2019 for management of their disease.

Routine patient follow-ups included yearly ambulatory visits with a cardiologist from one of our medical centers and, for patients complaining of palpitations or lightheadedness, or presenting with LV systolic dysfunction, an echocardiogram and 24-h ambulatory electrocardiogram. The prescription of cardioactive treatments, including ACE-i, was left to the judgment of their general cardiologist.

We retrospectively entered in a dedicated database the results of all neurological and cardiac investigations contained in the patients' medical records. The vital status of patients who were not followed by one of our institutions, or whose circumstances and cause of death were not known at the end of the observation period, was ascertained by contacting their primary physician. This study was approved by our local Ethics Committee (CPP Ile de France VI), which, for this retrospective study waived the formal patient consents. 


\section{Patient selection}

From the overall population included in the Becker Heart Registry, we excluded patients presenting with 1) a concomitant disorder that might influence the cardiac involvement by the disease, 2) LVEF $<40 \%$ at first referral, 3) LVEF $\geq 50 \%$ at first visit to our cardiology unit and during follow up, or 4) treatment with an ACE-i or angiotensin receptor blocker initiated while LVEF was $\geq 50 \%$ for prevention of $\mathrm{HF}$ or systemic hypertension.

We included all other patients presenting at first referral or during follow-up with a LVEF between 40 and $49 \%$ and divided them between 1) early ACE-i treatment group, if initiated while LVEF was between 40 and $49 \%$, and 2) conventional ACE-i treatment group, if initiated in presence of a LVEF $<40 \%$ diagnosed during follow-up.

\section{Study endpoints}

The primary endpoint of the study was hospitalization for management of HF. One specificity of our reference centers is that all patient hospitalized for heart failure are referred to a unique cardiology department in Cochin Hospital, reducing the variability regarding criteria for admissions for HF. An adjudication committee, composed of two of the authors (LM, KW) unaware of the patients' characteristics and treatment strategy, reviewed the data and assigned the hospitalizations as prompted by HF, based on prespecified criteria [19]. The secondary study endpoint was a decrease in LVEF to $<35 \%$.

\section{Statistical analyses}

Continuous variables are presented as means \pm standard deviations or medians (interquartile range), as appropriate. Categorical variables are presented as counts and percentages.

Since this observational study was not randomized, several unbalanced baseline risk factors may have biased the comparisons between early and conventional ACE-i treatment groups. A propensity-based approach was used to limit these biases [20]. The propensity score is the probability of patient assignment to a particular treatment group based on a set of observed covariates. This probability was modeled, using a multiple variables logistic regression, in which the treatment regimen was the dependent and a set of baseline characteristics was the independent variable. Covariates, identified as potential confounders based on prior publications, included LVEF, age at inclusion in the study, beta-adrenergic blockade, left ventricle dilatation, prominent $\mathrm{Q}$ or $\mathrm{R}$ waves and QRS duration on the electrocardiogram, systolic blood pressure and loss of ambulation. The individual propensity score derived from this model was then used in an inverse probability of treatment weighting (IPTW) where weighting is defined as the inverse of the probability of receiving the treatment actually received [20,21].

The success of the propensity score was ascertained by the balance of baseline characteristics after IPTW. The balance of each variable between the 2 groups was evaluated by the standardized difference (i.e. the absolute difference in sample means divided by an estimate of the pooled standard deviation of the variable expressed as a percentage) and the ratio of the variances of the covariates residuals after IPTW. Balancing was considered successful when all absolute standardized mean differences (aSMD) for the covariates identified as potential confounders were $<0.25$ and the ratio of the variances was between 0.5 and 2.0 [22].

Time-to-event curves were constructed using the Kaplan-Meier product limit estimator, and Cox proportional hazards models were used to compare the event hazards between the early ACE-i- and the conventional ACE-i-treated groups, both taking into account the IPTW. The baseline was defined as the time of first diagnosis of LVEF between $40 \%$ and $49 \%$. The observation period ended when $<15 \%$ of patients were observable. The proportionality of hazard assumption was evaluated by fitting the interaction between a variable of interest and the linear follow-up time. The hazard ratios (HR) are expressed with their $95 \%$ confidence intervals (CI). All tests were two-sided at the 0.05 significance level.

The statistical analyses were performed using the Statistical Analysis Software 9.4 (SAS Institute Inc., Cary, North Carolina).

\section{RESULTS}

\section{Patient selection}

The flow of patients selected for the present study is shown in Fig. 1. Among the 183 patients included in the Becker Heart Registry, we excluded 2 presenting with ischemic heart disease, 4 who had undergone cardiac transplantation prior to first referral, and 2 whose data were missing. Of the 175 remaining 


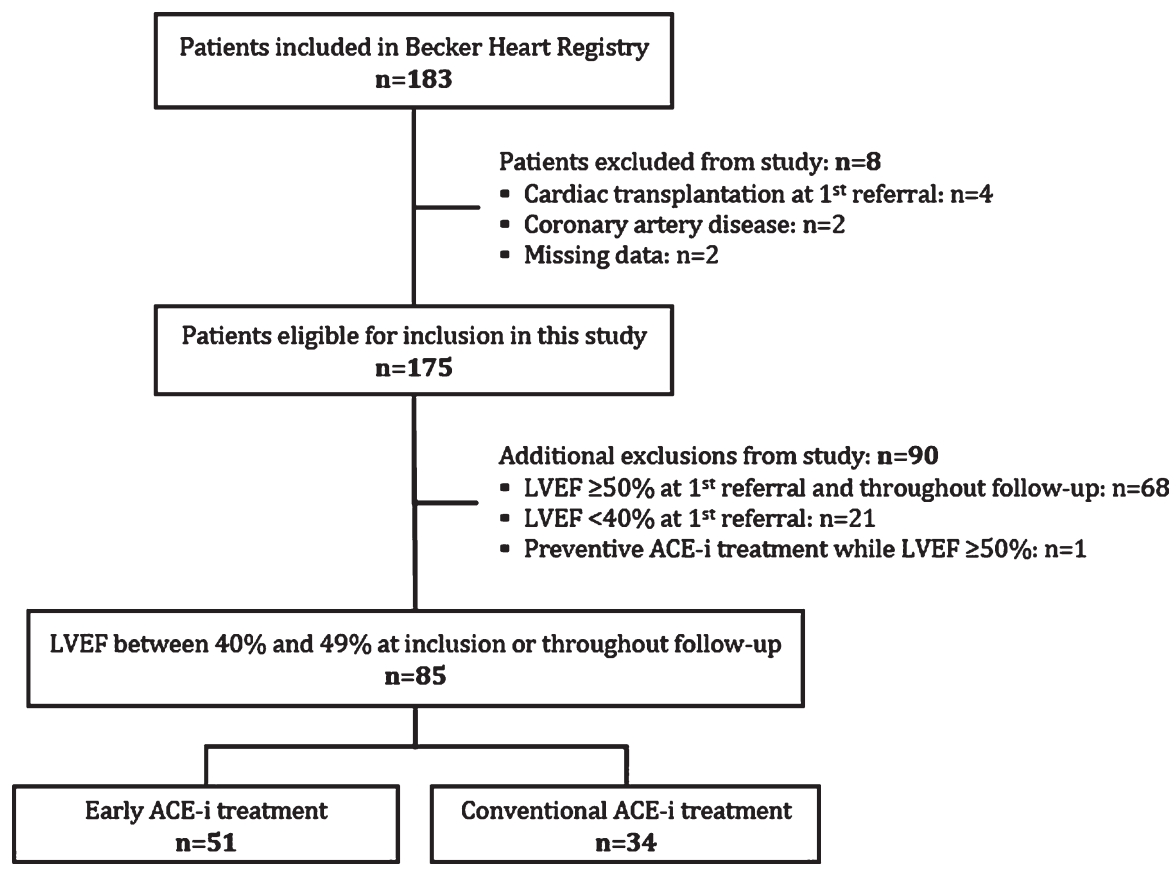

Fig. 1. Extraction of the study sample. ACE-i = angiotensin-converting enzyme inhibitor; LVEF= left ventricular ejection fraction.

patients, we excluded 21 with LVEF $<40 \%$ at first referral, 68 with LVEF $\geq 50 \%$ at first referral and throughout follow-up, and 1 treated prophylactically with an ACE-i while LVEF was $\geq 50 \%$. We ultimately included 85 patients with LVEF between 40 and $49 \%$, of whom 51 received early and 34 conventional treatment with an ACE-i, respectively at baseline and in presence of a LVEF $<40 \%$ diagnosed during follow-up. In all patients from the early treatment group, ACE inhibitors were initiated at first diagnosis of LVEF below 50\%. As no patients stopped the ACE-I treatment during follow-up, treatment duration corresponds to the follow-up duration in the study. The median number of visits per year of follow-up was 0.58 [0.36-0.95] in patients treated early, versus $0.61[0.46-0.86]$ in the conventionally treated group $(p=0.665)$. The inclusion periods in the early and conventional treatment groups were similar $(p=0.129)$, with, respectively, 15 and 6 patients included between years 1990 and 2000, 24 and 13 patients between years 2000 and 2010, and 12 and 15 patients between years 2010 and 2020.

\section{Baseline characteristics}

The baseline characteristics before and after IPTW are shown in Table 1. After IPTW, the baseline characteristics of patients treated with ACE-i early versus conventionally were similar, including mean age $(30.8 \pm 11.9$ vs. $31.1 \pm 14.3$ years; aSMD = $0.02)$, QRS duration $(95.6 \pm 12.0$ vs. $95.5 \pm 13.0 \mathrm{~ms}$; aSMD $=0.01)$ and other electrocardiographic measurements, use of beta-adrenergic blockers (13.3 vs. $11.3 \%$; aSMD $=0.06)$ and mean $\operatorname{LVEF}(47.7 \pm 3.1$ vs. $47.4 \pm 2.9 \%$; aSMD =0.11). All absolute standardized differences for potentially confounding variables were $<25 \%$ and the variance ratios between 0.5 and 2.0, confirming that the propensity score was correctly calculated.

\section{Hospitalization for management of heart failure}

Over median follow-ups of 12.9 [6.1-6.0] and 7.6 [5.0-13.3] years, 2 of 51 patients (3.9\%) treated early and 4 of $34(11.8 \%)$ treated conventionally with ACE-i had hospitalization for management of HF, with median times-to-events of 7.0 [3.9-10.2] and 7.6 years [4.4-12.9], respectively (Table 2; Fig. 2). Among these 6 patients, 2 died of endstage HF and 2 underwent heart transplantation. By Cox model analysis after IPTW, early ACE-i treatment was associated with a significantly lower risk of hospitalization for HF (HR 0.151 ; 95\% CI 0.028 to 0.822 , $p=0.029$; Table 3). 
Table 1

Baseline patient characteristics before and after inverse probability of treatment weighting

\begin{tabular}{|c|c|c|c|c|c|c|}
\hline \multirow[t]{3}{*}{ Characteristics } & \multicolumn{3}{|c|}{ Before IPT weighting } & \multicolumn{3}{|c|}{ After IPT weighting } \\
\hline & \multicolumn{2}{|c|}{ ACE-i } & \multirow[t]{2}{*}{ aSMD } & \multicolumn{2}{|c|}{ ACE-i } & \multirow[t]{2}{*}{ aSMD } \\
\hline & $\begin{array}{l}\text { Early } \\
(n=51)\end{array}$ & $\begin{array}{c}\text { Conventional } \\
\quad(n=34)\end{array}$ & & $\begin{array}{l}\text { Early } \\
(n=51)\end{array}$ & $\begin{array}{c}\text { Conventional } \\
(n=34)\end{array}$ & \\
\hline Age at registry inclusion, $y$ & $30 \pm 12$ & $34 \pm 14$ & 0.29 & $31 \pm 12$ & $31 \pm 14$ & 0.02 \\
\hline Loss of ambulation & $9(18)$ & $9(27)$ & 0.21 & $10(20)$ & $8(24)$ & 0.09 \\
\hline Diabetes & $4(7.8)$ & $2(5.9)$ & 0.08 & $4.3(8.7)$ & $1.3(3.7)$ & 0.21 \\
\hline Systemic hypertension & $10(20)$ & $5(15)$ & 0.13 & $10(21)$ & $5(15)$ & 0.14 \\
\hline \multicolumn{7}{|l|}{ Blood pressure, $\mathrm{mmHg}$} \\
\hline Systolic & $122 \pm 17$ & $121 \pm 16$ & 0.10 & $122 \pm 16$ & $123 \pm 16$ & 0.02 \\
\hline Diastolic & $70 \pm 14$ & $72 \pm 12$ & 0.16 & $71 \pm 14$ & $72 \pm 13$ & 0.12 \\
\hline Heart rate, bpm & $73 \pm 14$ & $74 \pm 15$ & 0.10 & $74 \pm 13$ & $74 \pm 14.0$ & 0.03 \\
\hline \multicolumn{7}{|l|}{ Electrocardiogram } \\
\hline \multicolumn{7}{|l|}{ Intervals, ms } \\
\hline PR & $136.1 \pm 15.0$ & $141 \pm 20$ & 0.28 & $137 \pm 15$ & $142 \pm 19$ & 0.25 \\
\hline QR & $95 \pm 12$ & $99 \pm 15$ & 0.26 & $96 \pm 12$ & $96 \pm 13$ & 0.01 \\
\hline Abnormal $\mathrm{Q}$ or $\mathrm{R}$ waves & $48(94)$ & $32(94)$ & 0.00 & $46(94)$ & $33(94)$ & 0.02 \\
\hline \multicolumn{7}{|l|}{ Echocardiogram } \\
\hline \multicolumn{7}{|l|}{ Left ventricular } \\
\hline Ejection fraction, $\%$ & $48 \pm 3$ & $48 \pm 3$ & 0.08 & $48 \pm 3.1$ & $47 \pm 3$ & 0.11 \\
\hline Dilatation & $14(28)$ & $5(15)$ & 0.32 & $12(24)$ & $10(27)$ & 0.09 \\
\hline Beta-adrenergic blockers & $9(18)$ & $2(6)$ & 0.37 & $7(13)$ & $4(11)$ & 0.06 \\
\hline
\end{tabular}

Values are means $\pm \mathrm{SD}$ or numbers $(\%)$ of observations. ACE- $\mathrm{i}=$ angiotensin-converting enzyme inhibitor; $\mathrm{aSMD}=$ absolute standardized mean difference; IPT=inverse probability of treatment; $\mathrm{LV}=$ left ventricular.

Table 2

Cardiovascular events during follow-up

\begin{tabular}{lcc}
\hline & \multicolumn{2}{c}{ ACE-i treatment } \\
\cline { 2 - 3 } & $\begin{array}{c}\text { Early } \\
(n=51)\end{array}$ & $\begin{array}{c}\text { Conventional } \\
(n=34)\end{array}$ \\
\hline $\begin{array}{l}\text { Hospitalization for management } \\
\text { of heart failure }\end{array}$ & & \\
$\quad \begin{array}{l}\text { Number of events } \\
\text { Median time to events, y }\end{array}$ & $7[4-10]$ & $8[4-13]$ \\
Clinical presentation & & \\
$\quad$ Endstage heart failure & $1(2)$ & $3(9)$ \\
$\quad \begin{array}{l}\text { Death due to heart failure } \\
\text { Cardiac transplantation }\end{array}$ & $1(2)$ & $1(3)$ \\
$\begin{array}{l}\text { Decrease in left ventricular } \\
\text { ejection fraction to <35\% }\end{array}$ & 0 & $2(6)$ \\
Number of events & & \\
Median time to events, y & $7[4-10]$ & $4[3-7]$ \\
\hline
\end{tabular}

Values are numbers (\%) of observations or median [interquartile range]. ACE- $\mathrm{i}=$ angiotensin-converting enzyme inhibitor.

\section{Decrease in left ventricular ejection fraction below $35 \%$}

LVEF decreased to $<35 \%$, in 9 of 51 patients treated early (17.6\%) and in 10 of $34(29.4 \%)$ patients treated conventionally with ACE-i, over median follow-ups of 8.6 [4.3-14.9] and 5.4 years [4.0-8.5], respectively. The median times-to-events were 7.0 [4.0-9.7] and 4.2 years [3.4-6.9], respectively (Table 2; Fig. 2). By Cox model analysis after IPTW, early treatment with ACE-i was associated with a significantly lower risk of decrease in LVEF below 35\% (HR 0.290; 95\% CI 0.121 to 0.694; $p=0.005$; Table 3 ). The yearly absolute change in LVEF was $-0.23 \pm 1.73$ in the early treatment group versus $-0.60 \pm 1.97$ in the conventional treatment group $(p=0.791)$.

\section{DISCUSSION}

Our study shows that, compared with treatment of HF guided by professional guidelines [18], the introduction of an ACE-i when LVEF falls below 50\% improves the long-term prognosis of patients suffering from Becker MD.

These findings are concordant with those of prior studies of Duchenne MD, the most severe dystrophinopathy [12-14], particularly with those of a randomized study, in which the prophylactic use of perindopril in patients with preserved LVEF, between the ages of 8 and 13 years, prevented the development of dilated cardiomyopathy at 5 years of follow-up [16]. Furthermore, after the prolongation of the trial follow-up to 10 years, the survival rate was $93 \%$ in the perindopril in contrast with $66 \%$ in the placebo group, corresponding to an odds ratio of 0.15 [17]. The magnitude of benefit conferred by ACE-i in our study is similar to that observed in that randomized study, and adds support to their reputed high efficacy in the prevention of myocardial dysfunction in 

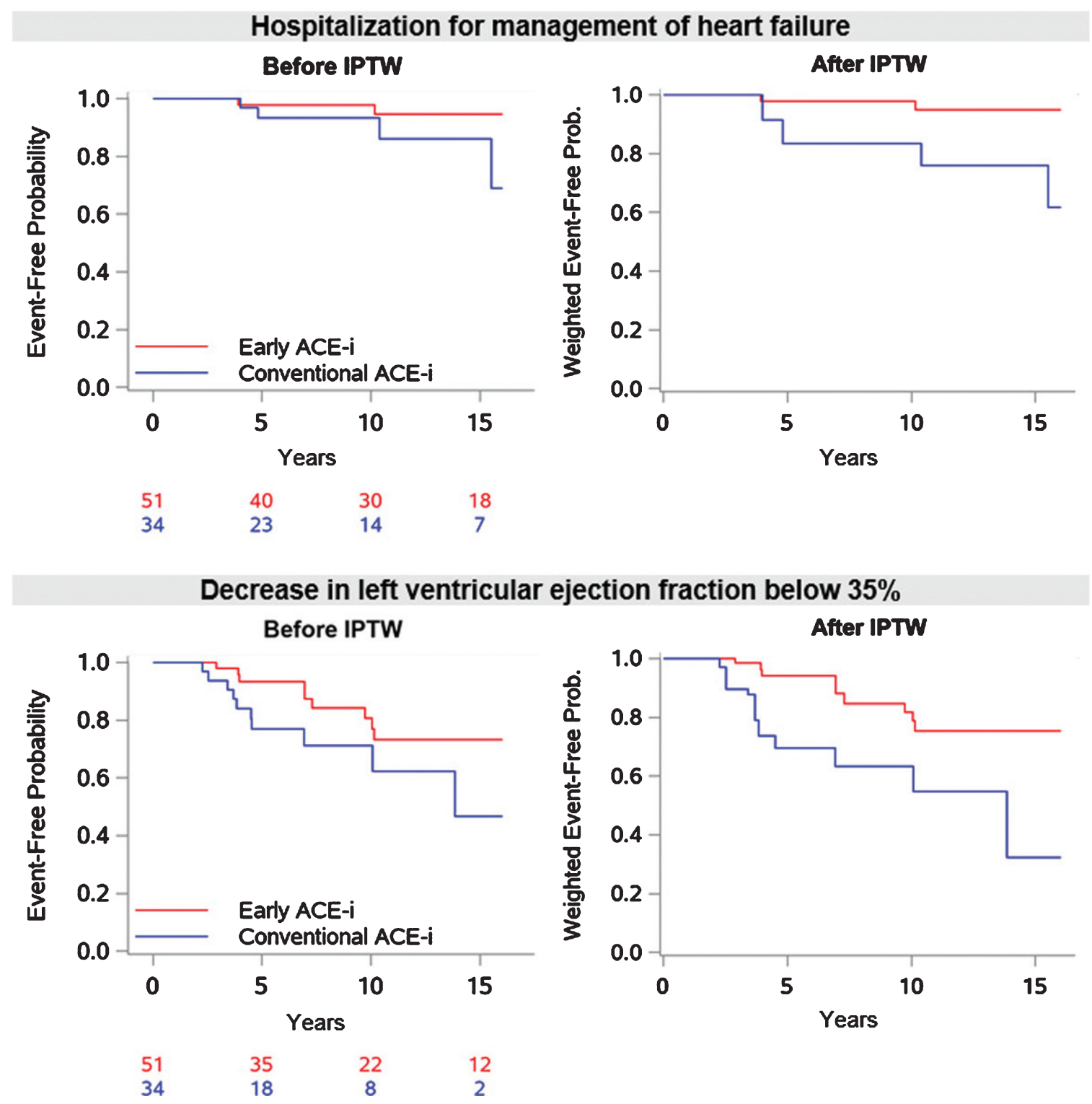

Fig. 2. Hospitalization for management of heart failure and decrease in left ventricular ejection fraction to $<35 \%$ during follow-up. IPTW = inverse probability of treatment weighting; ACE-i = angiotensin-converting enzyme inhibitor.

Table 3

Effects of early versus conventional prescription of angiotensinconverting enzyme inhibitors in the Cox model after inverse probability of treatment weighting

\begin{tabular}{lcc}
\hline & $\begin{array}{c}\text { Hazard ratio } \\
\text { [95\% confidence interval] }\end{array}$ & $p$ \\
\hline $\begin{array}{c}\text { Hospitalization for } \\
\text { management of heart failure }\end{array}$ & $0.151[0.028-0.822]$ & 0.029 \\
$\begin{array}{c}\text { Decrease in left ventricular } \\
\text { ejection fraction to }<35 \%\end{array}$ & $0.290[0.121-0.694]$ & 0.005 \\
\hline
\end{tabular}

dystrophinopathies, especially when introduced early in the course of the disease, with their preventive benefit becoming manifest after 5 to 10 years of follow-up.

The results of our study strongly support the systematic use of ACE-i in patients presenting with Becker MD as soon as the LVEF falls below 50 . While, as found in Duchenne MD, there is currently no evidence that patients with Becker MD whose LVEF is $\geq 50 \%$ should be prescribed ACE-i, their potential benefit should nevertheless be further 
examined on the basis of different criteria, and the criteria of eligibility for this treatment may need to be revisited in the future. The presence of myocardial fibrosis might be an important observation, since it has been correlated with disease progression in patients presenting with Duchenne or Becker MD, particularly in presence of a preserved LVEF [23-25]. The combination of disease characteristics, such as fibrosis burden, blood biomarkers, myocardial strain and LVEF may refine the selection of candidates for cardioprotective treatments. It also remains to be determined whether other treatments of HF, for example mineralocorticoid receptor antagonists, perhaps combined with ACE-i, are beneficial in Becker as has been shown in Duchenne MD [26-28].

From a broader perspective, our study contributes to the question regarding the merit of prescribing treatments of HF in non-ischemic cardiomyopathy earlier than recommended by the professional guidelines. An increasing proportion of patients with myocardial disease and preserved LV systolic function are detected during screenings of families with inherited cardiomyopathies or of patients with systemic or neuromuscular disorders [29]. It remains unclear whether ACE-i and other treatments of HF are effective in presence of a normal or mildly impaired LVEF, before thresholds are set and validated in studies of the general population. Our observations suggest that the potential prognostic benefit, safety and cost-effectiveness of prophylactic strategies need to be studied in high-risk disorders.

\section{Limitations of our study}

The first limitation of our study is its observational design, which may have biased the estimation of the ACE-i treatment effect. Using a propensity analysis, which most reliably limits the influence of potential confounders in this setting [30] we found a strong and highly significant association between ACE-i treatment and clinically important cardiac endpoints. Since patients treated with ACE-i may have been followed more closely than the untreated patients, perhaps resulting in the earlier detection and treatment of overt LV dysfunction, we compared and found a similar number of cardiological evaluations during follow-up in both groups. The retrospective design of our study is another limitation, which precluded a consistent prescription of the types and doses of ACE-i. Patients from the conventional treatment group were addressed later than the others but this was taken into consideration in the analysis via the propensity score.

\section{CONCLUSIONS}

In patients with Becker MD, treatment with ACE-i introduced when LVEF fell below 50\%, instead of $40 \%$ as recommended by the guidelines of professional societies, was associated with better cardiac outcomes.

\section{ACKNOWLEDGMENTS}

This study was funded by grants from AFMTéléthon (Association Française contre les Myopathies).

\section{CONFLICT OF INTEREST}

The authors have no conflict of interest to disclose.

\section{SUPPLEMENTARY MATERIAL}

The supplementary material is available in the electronic version of this article: https://dx.doi.org/ 10.3233/JND-200620.

\section{REFERENCES}

[1] Bushby KM, Gardner-Medwin D, Nicholson LV, Johnson MA, Haggerty ID, Cleghorn NJ, et al. The clinical, genetic and dystrophin characteristics of Becker muscular dystrophy. II. Correlation of phenotype with genetic and protein abnormalities. J Neurol févr. 1993;240(2):105-12.

[2] Hoogerwaard EM, de Voogt WG, Wilde AA, van der Wouw PA, Bakker E, van Ommen GJ, et al. Evolution of cardiac abnormalities in Becker muscular dystrophy over a 13-year period. J Neurol oct. 1997;244(10):657-63

[3] Chamberlain JS, Gibbs RA, Ranier JE, Nguyen PN, Caskey CT. Deletion screening of the Duchenne muscular dystrophy locus via multiplex DNA amplification. Nucleic Acids Res 9 déc. 1988;16(23):11141-56.

[4] Comi GP, Prelle A, Bresolin N, Moggio M, Bardoni A, Gallanti A, et al. Clinical variability in Becker muscular dystrophy. Genetic, biochemical and immunohistochemical correlates. Brain J Neurol févr. 1994;117 (Pt 1):1-14.

[5] Koenig M, Beggs AH, Moyer M, Scherpf S, Heindrich $\mathrm{K}$, Bettecken T, et al. The molecular basis for Duchenne versus Becker muscular dystrophy: Correlation of severity with type of deletion. Am J Hum Genet oct. 1989;45(4): 498-506.

[6] Emery AEH. Duchenne muscular dystrophy. 3rd ed. Oxford; New York: Oxford University Press; 2003. pp. 270.

[7] Melacini P, Fanin M, Danieli GA, Fasoli G, Villanova C, Angelini C, et al. Cardiac involvement in Becker muscular dystrophy. J Am Coll Cardiol. déc. 1993;22(7):1927-34.

[8] Saito M, Kawai H, Akaike M, Adachi K, Nishida Y, Saito S. Cardiac dysfunction with Becker muscular dystrophy. Am Heart J sept. 1996;132(3):642-7.

[9] Park OY, Ahn Y, Park WS, Lim JH, Park HW, Kim JH, et al. Rapid progression from hypertrophic cardiomyopathy to 
heart failure in a patient with Becker's muscular dystrophy. Eur J Heart Fail juin. 2005;7(4):684-8.

[10] Russo V, Papa AA, Williams EA, Rago A, Palladino A, Politano L, et al. ACE inhibition to slow progression of myocardial fibrosis in muscular dystrophies. Trends Cardiovasc Med. 2018;28(5):330-7.

[11] Silva MC, Magalhães TA, Meira ZMA, Rassi CHRE, Andrade AC de S, Gutierrez PS, et al. Myocardial Fibrosis Progression in Duchenne and Becker Muscular Dystrophy: A Randomized Clinical Trial. JAMA Cardiol. 01 2017; 2(2):190-9.

[12] Dittrich S, Graf E, Trollmann R, Neudorf U, Schara U, Heilmann A, et al. Effect and safety of treatment with ACE-inhibitor Enalapril and $\beta$-blocker metoprolol on the onset of left ventricular dysfunction in Duchenne muscular dystrophy-a randomized, double-blind, placebo-controlled trial. Orphanet J Rare Dis. 10 2019;14(1):105.

[13] Allen HD, Flanigan KM, Thrush PT, Dvorchik I, Yin H, Canter C, et al. A randomized, double-blind trial of lisinopril and losartan for the treatment of cardiomyopathy in duchenne muscular dystrophy. PLoS Curr. 12 déc. 2013;5.

[14] Viollet L, Thrush PT, Flanigan KM, Mendell JR, Allen HD. Effects of angiotensin-converting enzyme inhibitors and/or beta blockers on the cardiomyopathy in Duchenne muscular dystrophy. Am J Cardiol. 1 juill. 2012;110(1):98-102.

[15] Bourke JP, Bueser T, Quinlivan R. Interventions for preventing and treating cardiac complications in Duchenne and Becker muscular dystrophy and X-linked dilated cardiomyopathy. Cochrane Database Syst Rev. 16 oct. 2018;10: CD009068.

[16] Duboc D, Meune C, Lerebours G, Devaux J-Y, Vaksmann G, Bécane H-M. Effect of perindopril on the onset and progression of left ventricular dysfunction in Duchenne muscular dystrophy. J Am Coll Cardiol. 15 mars. 2005;45(6):855-7.

[17] Duboc D, Meune C, Pierre B, Wahbi K, Eymard B, Toutain A, et al. Perindopril preventive treatment on mortality in Duchenne muscular dystrophy: 10 years' follow-up. Am Heart J. sept. 2007;154(3):596-602.

[18] Yancy CW, Jessup M, Bozkurt B, Butler J, Casey DE, Colvin MM, et al. 2017 ACC/AHA/HFSA Focused Update of the 2013 ACCF/AHA Guideline for the Management of Heart Failure: A Report of the American College of Cardiology/American Heart Association Task Force on Clinical Practice Guidelines and the Heart Failure Society of America. J Am Coll Cardiol. 08. 2017;70(6):776-803.

[19] Hicks KA, Tcheng JE, Bozkurt B, Chaitman BR, Cutlip DE, Farb A, et al. 2014 ACC/AHA Key Data Elements and Definitions for Cardiovascular Endpoint Events in Clinical Trials: A Report of the American College of Cardiol-
ogy/American Heart Association Task Force on Clinical Data Standards (Writing Committee to Develop Cardiovascular Endpoints Data Standards). J Am Coll Cardiol. 28 juill. 2015;66(4):403-69.

[20] Rosenbaum P, Rubin D. The central role of the propensity score in observational studies for causal effects. Biometrika. 1983;70(1):41-55.

[21] Pirracchio R, Resche-Rigon M, Chevret S. Evaluation of the Propensity score methods for estimating marginal odds ratios in case of small sample size. BMC Med Res Methodol. déc. 2012;12(1):70.

[22] Stuart EA. Matching methods for causal inference: A review and a look forward. Stat Sci Rev J Inst Math Stat. 1 févr. 2010;25(1):1-21.

[23] Florian A, Ludwig A, Engelen M, Waltenberger J, Rösch $\mathrm{S}$, Sechtem U, et al. Left ventricular systolic function and the pattern of late-gadolinium-enhancement independently and additively predict adverse cardiac events in muscular dystrophy patients. J Cardiovasc Magn Reson Off J Soc Cardiovasc Magn Reson. 25 sept. 2014;16:81.

[24] Marty B, Gilles R, Toussaint M, Béhin A, Stojkovic T, Eymard B, et al. Comprehensive evaluation of structural and functional myocardial impairments in Becker muscular dystrophy using quantitative cardiac magnetic resonance imaging. Eur Heart J Cardiovasc Imaging. 1 août. 2019;20(8): 906-15.

[25] Menon SC, Etheridge SP, Liesemer KN, Williams RV, Bardsley T, Heywood MC, et al. Predictive value of myocardial delayed enhancement in Duchenne muscular dystrophy. Pediatr Cardiol. oct. 2014;35(7):1279-85.

[26] Raman SV, Hor KN, Mazur W, Halnon NJ, Kissel JT, He $\mathrm{X}$, et al. Eplerenone for early cardiomyopathy in Duchenne muscular dystrophy: A randomised, double-blind, placebo-controlled trial. Lancet Neurol. févr. 2015;14(2): 153-61.

[27] Raman SV, Hor KN, Mazur W, He X, Kissel JT, Smart S, et al. Eplerenone for early cardiomyopathy in Duchenne muscular dystrophy: Results of a two-year open-label extension trial. Orphanet J Rare Dis. 20. 2017;12(1):39.

[28] Raman SV, Hor KN, Mazur W, Cardona A, He X, Halnon N, et al. Stabilization of Early Duchenne Cardiomyopathy With Aldosterone Inhibition: Results of the Multicenter AIDMD Trial. J Am Heart Assoc. 2019;8(19):e013501.

[29] Hershberger RE, Siegfried JD. Update 2011: Clinical and genetic issues in familial dilated cardiomyopathy. J Am Coll Cardiol. 19 avr. 2011;57(16):1641-9.

[30] D'Agostino RB, D'Agostino RB. Estimating treatment effects using observational data. JAMA. 17 janv. 2007; 297(3):314-6. 